\title{
Analisis dan Perancangan Software Simulasi Pertumbuhan Kebutuhan Proses Bisnis Sekolah Berdasarkan Standar Nasional Pendidikan (SNP)
}

\author{
Faradilah Putri Damayant ${ }^{1, *}$, Betty Faizatul Layli Ulfiatin ${ }^{2}$, Berlian Fatimah Haryoko ${ }^{3}$, Muhammad \\ Ainul Yaqin ${ }^{4}$ \\ Jurusan Teknik Informatika, Universitas Islam Negeri Maulana Malik Ibrahim, Indonesia \\ 118650022@student.uin-malang.ac.id; ${ }^{2} 18650013 @$ student.uin-malang.ac.id; ${ }^{3} 18650023 @$ student.uin-malang.ac.id; \\ 4yaqinov@ti.uin-malang.ac.id \\ * corresponding author
}

INFO ARTIKEL

\section{Sejarah Artikel}

Diterima: 21 Desember 2019

Direvisi: 13 April 2020

Diterbitkan: 30 Agustus 2020

Kata Kunci

Proses Bisnis

Standar Nasional Pendidikan

Metode Waterfall

Simulasi Pertumbuhan

\section{ABSTRAK}

Penelitian ini bertujuan untuk menghasilkan suatu program yang dapat menentukan kebutuhan sekolah secara otomatis berdasarkan Standar Nasional Pendidikan. Program ini dibuat dengan cara merangkum aturanaturan yang telah ditetapkan oleh badan Standar Nasional Pendidikan dan dibuat melalui Microsoft Excel. Data yang dibutuhkan adalah jumlah siswa dalam satu sekolah. Hasil penelitian ini berupa grafik kebutuhan proses bisnis sekolah yang bisa didapatkan dengan menginputkan jumlah seluruh siswa dalam satu sekolah. Poses penghitungan tersebut adalah implementasi dari syarat dan rumus yang telah kita rangkum berdasarkan 8 SNP aturan - aturan lain yang berlaku. Semakin banyak jumlah siswa dalam satu sekolah, maka akan semakin banyak pula kebutuhan sekolah yang diperlukan. Baik kebutuhan sarana dan prasarana maupun luas sekolah begitu pula mengenai masalah dana.

\section{PENDAHULUAN}

Proses Bisnis adalah serangkaian aktivitas yang dilakukan oleh suatu bisnis dimana mencakup inisiasi input, transformasi dari suatu informasi, dan menghasilkan output [1]. Sekolah yang baik adalah sekolah yang mampu menyediakan berbagai kebutuhan seluruh siswa dengan perhitungan yang tepat berdasar aturan yang telah ditetapkan oleh badan yang berwenang. Kebutuhan tiap sekolah mulai dari sekolah itu baru dirintis hingga mencapai jumlah siswa maksimum mengakibatkan naik turunnya grafik proses bisnis yang dilakukan. Proses naik turun inilah, dapat dilakukan prediksi dengan membuat rancangan software simulasi pertumbuhan kebutuhan proses bisnis sekolah sehingga pada saat terjadi peningkatan jumlah siswa, sekolah tersebut mampu menyiapkan segala kebutuhan yang memiliki kemungkinan terjadinya peningkatan [2]. Contoh kebutuhan yang memiliki kemungkinan akan selalu mengalami peningkatan adalah jumlah kelas, kebutuhan buku perpustakaan, kebutuhan ruang guru, dan lain sebagainya. Kebutuhan proses bisnis sekolah disini, berdasarkan aturan - aturan yang telah ditetapkan oleh Standar Nasional Pendidikan (SNP).

Standar Nasional Pendidikan (SNP) merupakan kriteria minimal tentang berbagai aspek yang relevan dalam pelaksanaan sistem pendidikan nasional dan harus dipenuhi oleh penyelenggara dan/atau satuan pendidikan di seluruh wilayah hukum Negara Kesatuan Republik Indonesia. SNP sendiri memiliki 8 standar yang dalam pelaksanaannya, kita harus mampu menerapkan semua standar dengan maksimal sehingga dapat menciptakan suatu sekolah yang memenuhi kriteria dalam proses bisnisnya [3][4]. Kontribusi dalam penelitian 
merupakah suatu hal yang sangat penting. Mahasiswa beranggapan bahwa kontribusi yang dimaksud adalah kontribusi kepada masyarakat. Namun, kontribusi kepada masyarakat adalah hal yang sulit untuk didapatkan tolak ukurnya. Maka, cukup dengan berfokus pada tujuan penulisan, otomatis niat yang kita inginkan untuk tersalur kepada masyarakat akan lebih mudah dirasakan. Kontribusi penelitian ada dua acara, yaitu dengan kebaruan metode atau masalah penelitian yang kita pilih [5]. Penelitian yang kita lakukan menggunakan kontribusi penelitian dalam hal masalah penelitian yang diangkat. Hal ini kita lakukan karena penelitian - penelitian yang telah dilakukan sebelumnya hanya berfokus pada satu aspek, seperti pada bidang personalia dan belum mencakup 8 SNP yang telah ada. Sehingga kita membuat aturan/ rule yang telah mencakup 8 SNP tersebut.

Berdasarkan uraian singkat diatas, penulis memahami 8 SNP yang telah ditetapkan dengan membuat aturan - aturan/ rule setelah itu membuat perancangan software dengan masih menggunakan Microsoft Excel untuk melakukan perhitungan berbagai kebutuhan dengan input jumlah siswa dalam satu sekolah. Sehingga dengan diperolehnya jumlah berbagai kebutuhan tersebut, akan menghasilkan suatu grafik yang dapat menjadi tolak ukur untuk menambah berbagai kebutuhan yang diperlukan sekolah. Microsoft Excel kita pilih karena mudah dalam penggunaannya dan terdapat banyak sumber yang mampu menunjang dalam hal menyelesaikan perhitungan untuk mendapatkan grafik proses bisnis yang diinginkan [6][7]. Syarat - syarat dalam 8 SNP tidak dijabarkan secara singkat melainkan melalui pasal - pasal yang telah disepakati pemerintah pusat. Hal ini menjadi salah satu kendala untuk dapat merumuskan proses bisnis sekolah dengan tepat. Seperti yang kita tahu juga, semangat literasi masyarakat Indonesia masih cukup rendah dan untuk membaca semua pasal yang tercantum akan membutuhkan waktu yang cukup lama, maka dari itu perlu dilakukan analisis pola pertumbuhan kebutuhan sekolah agar permasalahan seputar ketimpangan jumlah siswa, tenaga pengajar, sarana dan prasarana dapat diminimalisir. Sehingga kami mengimplementasikan syarat - syarat tersebut dalam bentuk software agar dapat dengan mudah digunakan dan meminimalisir kesalahan dalam merumuskan kebutuhan proses bisnis sekolah. Penelitian - penelitian lanjutan yang akan menyempurnakan program, menunjukkan salah satu tolak ukur keberhasilan dari penelitian ini. Hal ini dikarenakan dalam penelitian ini, hanya berfokus pada perancangan system sehingga dengan adanya penelitian lanjutan akan lebih menyempurnakan program yang nantinya akan dibuat program yang sesungguhnya. Ini juga menunjukkan keakuratan rumus beserta data yang diinputkan.

\section{METODE}

Terdapat metode pengembangan software dalam menyelesaikan simulasi pertumbuhan proses bisnis sekolah ini. Disini kita menggunakan Metode Waterfall untuk melakukan penelitian ini [8]. Berikut penjelasan dari masing-masing poin Metode Waterfall, yaitu:

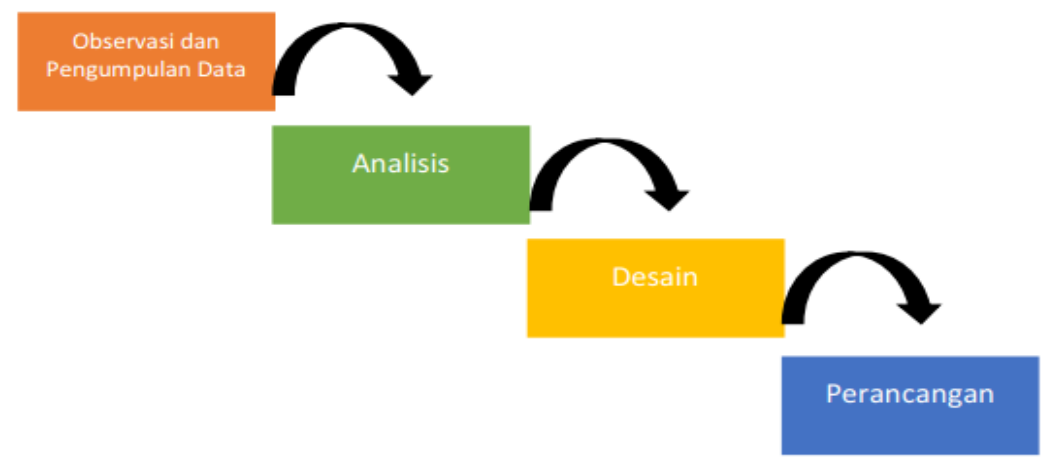

Gambar 1. Metode Waterfall 


\section{Observasi dan Pengumpulan Data}

Tahap observasi dan pengumpulan data ini, penulis melakukan studi literatur pada jurnal ilmiah, artikel, dan penelitian-penelitian sebelumnya yang berkesinambungan dengan topic. Penulis juga melakukan studi literatur tentang 8 SNP yakni Standar Kompetensi Lulusan, Standar Isi, Standar Proses, Standar Pendidikan dan Tenaga Kependidikan, Standar Sarana dan Prasarana, Standar Pengelolaan, Standar Pembiayaan Pendidikan, dan Standar Penilaian. Sedangkan kebutuhan proses bisnis meliputi 5M yakni Man, Machine, Money, Method, Materials. Kami juga melakukan wawancara langsung dengan pihak-pihak yang terkait dengan mengajukan sejumlah pertanyaan secara lisan dan dijawab secara lisan untuk memahami tujuan penelitian yang ingin dicapai.

\section{Analisa}

Tahap analisa ini, penulis menggunakan tipe analisis data kuantitatif dengan analisis regresi. Analisis regresi sendiri mampu menunjukkan prediksi yang akan terjadi antar variabel yang diinputkan dan dihasilkan. Pada tahap analisa ini, kita membuat aturan/ rule dari setiap standar yang telah ditetapkan dalam SNP. Aturan/ rule tersebut kita buat dengan membandingkan antar standar dalam SNP sehingga diperoleh data aturan yang saling berkesinambungan.

\section{Desain}

Tahap desain ini dilakukan sebelum melakukan proses coding pada tahap perancangan software. Hal ini ditujukan untuk memberi gambaran umum kepada pembuat sistem agar dapat mempermudah pengerjaan berdasarkan desain sistem yang diinginkan. Khusus untuk tampilan sendiri, kita desain menggunakan CorelDraw dan dibuat menarik agar user dapat dengan mudah menggunakan sistem yang akan kita buat. Sistem nantinya juga dilengkapi dengan pilihan untuk menampilkan berbagai aturan yang telah kita rangkum serta pilihan grafik masing - masing atau grafik secara keseluruhan. Pada tahap ini juga diatur mengalokasikan kebutuhan - kebutuhan sistem baik perangkat keras maupun perangkat lunak dengan membentuk arsitektur sistem secara keseluruhan.

\section{Perancangan Software Simulasi Pertumbuhan Proses Bisnis Sekolah}

Tahap perancangan software ini akan membuat rancangan software simulasi pertumbuhan berdasarkan data yang telah diperoleh pada tahap observasi dan pengumpulan data serta tahap analisa. Perancangan software dibuat sesuai analisa yang dibutuhkan dalam 8 SNP. Software yang digunakan untuk membuat aplikasi ini adalah Microsoft Excel dengan input jumlah siswa. Proses coding dimulai dari tahap ini. Disini kita menggunakan sistem dengan menginputkan rumus yang telah dibuat sebelumnya ke dalam Microsoft Excel. Output dari perancangan software ini adalah grafik yang digunakan untuk menunjukkan prediksi proses bisnis sekolah yang akan mengalami peningkatan. Sehingga didapatkan pola kebutuhan sekolah yang dibutuhkan.

\section{HASIL DAN PEMBAHASAN}

Dalam Badan Standar Nasional Pendidikan terdapat aturan - aturan yang dengan jelas telah mengatur berbagai jenjang pendidikan di Indonesia melalui 8 standar yang tercantum. Aturan tersebut dengan jelas harus dipatuhi berbagai jenjang pendidikan demi terwujudnya sekolah yang kondusif dan tidak over capacity. Pembahasan dalam jurnal yang kami buat terpusat pada jenjang Sekolah Dasar. Beban belajar di SD/ MI tahun I, II, dan III masing masing adalah 30, 32, 34 sedangkan untuk tahun IV, V, dan VI masing - masing adalah 36 jam setiap minggu. Jam belajar SD/ MI adalah 40 minggu [9] sebagaimana Tabel 1. 
Tabel 1. Struktur Kurikulum SD

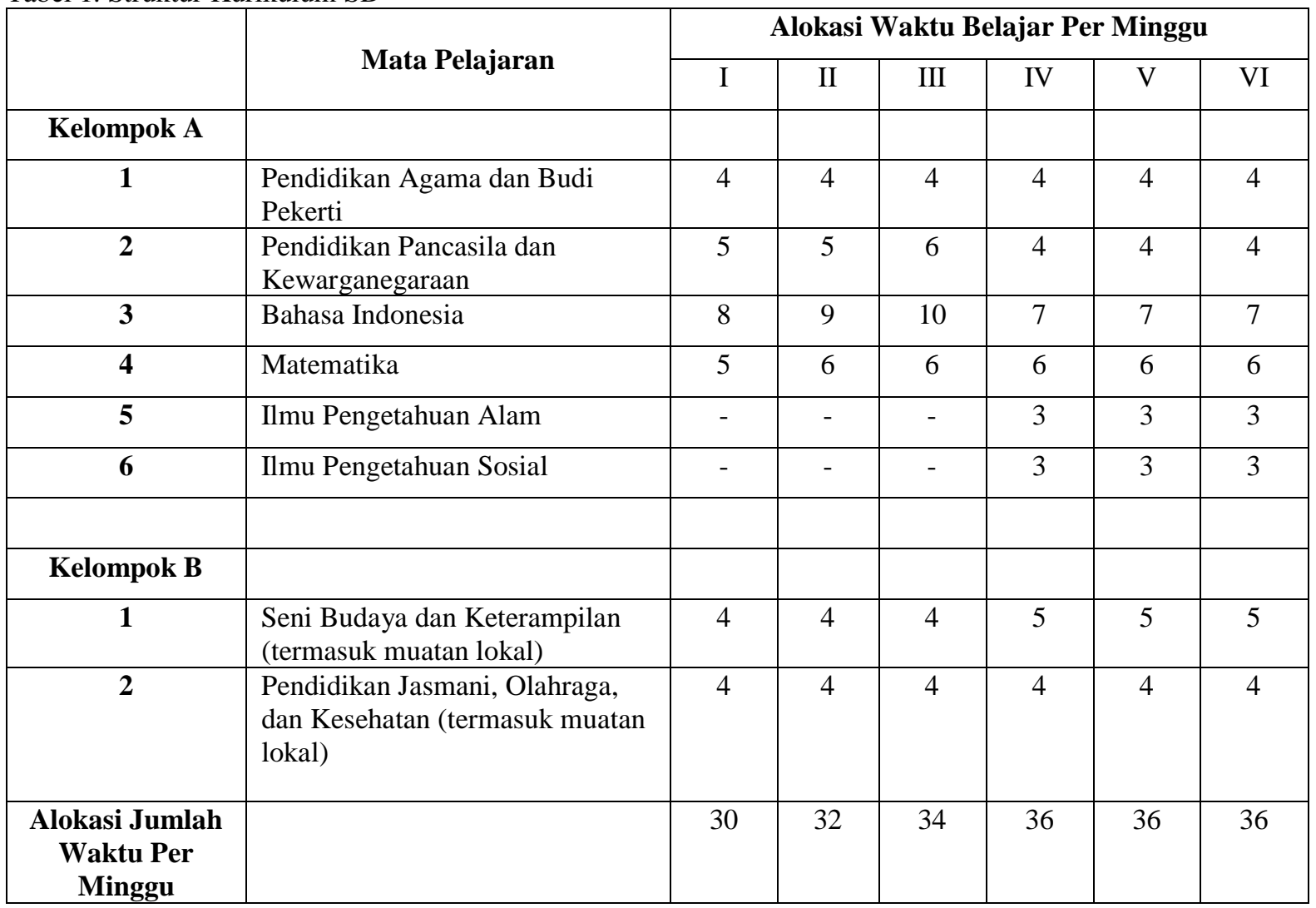

Kelompok A adalah mata pelajaran yang memberikan orientasi kompetensi lebih kepada aspek intelektual dan efektif yang kontennya dikembangkan oleh pusat. Kelompok B adalah mata pelajaran yang lebih menekankan pada aspek afektif dan psikomotor yang kontennya dikembangkan oleh pusat dan dilengkapi dengan konten lokal yang dikembangkan oleh pemerintah daerah. Mata pelajaran Seni Budaya dan Prakarya dapat memuat Bahasa Daerah. Selain kegiatan intrakurikuler seperti yang tercantum dalam struktur kurikulum, terdapat pula kegiatan ekstrakurikuler SD/ MI antara lain Pramuka (Wajib), Usaha Kesehatan Sekolah, dan Palang Merah Remaja. Berdasarkan 8 SNP yang telah ditetapkan, kami meringkas dan membuat syarat maksimum yang menjadi patokan maksimal untuk diterapkan oleh tiap - tiap sekolah, yaitu pada Tabel 2:

Tabel 2. Syarat 8 SNP

\begin{tabular}{|c|l|c|}
\hline \multirow{2}{*}{ NO } & \multicolumn{1}{|c|}{ Simulasi Pertumbuhan Kebutuhan Proses Bisnis Sekolah Berdasarkan SNP } \\
\cline { 2 - 3 } & \multicolumn{1}{|c|}{ Syarat } & Batasan Maksimum \\
\hline $\mathbf{1}$ & Jumlah Maksimum Siswa 1 Sekolah & 672 siswa \\
\hline $\mathbf{2}$ & Jumlah Maksimum Siswa 1 Kelas & 28 siswa \\
\hline $\mathbf{3}$ & Jumlah Mata Pelajaran SD & 8 mata pelajaran \\
\hline $\mathbf{4}$ & Jam Mengajar Maksimal Guru Tiap Minggu & 14 jam $/$ minggu \\
\hline $\mathbf{5}$ & Jumlah Petugas Perpus 1 Sekolah & $12 \mathrm{~m} \mathrm{orang}^{2}$ \\
\hline $\mathbf{6}$ & Luas Minimum UKS & $110 \mathrm{~m}^{2}$ \\
\hline $\mathbf{7}$ & Luas Kamar Mandi Cewek + Cowok & $18 \mathrm{~m}^{2}$ \\
\hline $\mathbf{8}$ & Luas Minimum Gudang & \multicolumn{1}{|c|}{} \\
\hline
\end{tabular}




\begin{tabular}{|c|l|c|}
\hline $\mathbf{9}$ & Dana BOS SD Tiap Siswa & $900.000 /$ tahun \\
\hline $\mathbf{1 0}$ & Beban Kerja Guru & $24 \mathrm{jam} / \mathrm{minggu}$ \\
\hline $\mathbf{1 1}$ & 1 Jam Pelajaran Siswa & 35 menit \\
\hline
\end{tabular}

Tabel 3. Aturan Jumlah Siswa per Rombongan

\begin{tabular}{|c|c|c|}
\hline NO & $\begin{array}{c}\text { Banyak Rombongan } \\
\text { Belajar }\end{array}$ & $\begin{array}{c}\text { Jumlah Siswa per } \\
\text { Rombongan }\end{array}$ \\
\hline $\mathbf{1}$ & 6 & $1-168$ \\
\hline $\mathbf{2}$ & $7-12$ & $167-336$ \\
\hline $\mathbf{3}$ & $13-18$ & $337-504$ \\
\hline $\mathbf{4}$ & $19-24$ & $505-672$ \\
\hline
\end{tabular}

Tabel 2 diperoleh dari proses observasi dan pengumpulan data yang kami kumpulkan dari lampiran Peraturan Menteri Pendidikan dan Kebudayaan yang tertuang dalam 8 SNP. Sedangkan Tabel 3 diperoleh dari proses observasi dan pengumpulan data yang kami kumpulkan khususnya dari lampiran Peraturan Menteri Pendidikan dan Kebudayaan Nomor 24 Tahun 2007 tentang Standar Sarana dan Prasarana Untuk Sekolah Dasar/ Madrasah Ibtidaiyah (SD/ MI), Sekolah Menengah Pertama/ Madrasah Tsanawiyah (SMP/ MTS), Dan Sekolah Menengah Atas/ Madrasah Aliyah (SMA/ MA)

\section{Rumus Berdasarkan Aturan yang Tertuang dalam Standar Nasional Pendidikan}

Badan Standar Nasional Pendidikan telah menetapkan aturan - aturan untuk proses bisnis sekolah bagi Indonesia [3][10][11][12][13][14][15][16][17]. Berikut kami rangkum aturan - aturan tersebut dalam bentuk rumus agar lebih mudah dipahami :

a. Rasio jumlah peserta didik : luas kelas $=$

- Luas Kelas $\leq 15 \mathrm{PD}=30 \mathrm{~m}^{2}$

- Luas Kelas $\geq 15$ PD = Jumlah Siswa $* 2 \mathrm{~m}^{2}$

b. Rasio jumlah peserta didik : jumlah kelas $=$

- Jumlah kelas $=$ Roundup $\left(\frac{\text { jumlah siswa }}{\text { jumlah maksimum siswa 1 kelas }}\right)$

c. Rasio jumlah siswa : kebutuhan kelas =

- Jumlah Kebutuhan Kelas = Jumlah Kelas

d. Rasio jumlah kebutuhan peserta didik : jumlah peserta didik $=$

- Jumlah kebutuhan peserta didik = jumlah peserta didik

e. Rasio jumlah guru : jumlah rombongan belajar $=$

- Jumlah Guru $=\operatorname{Roundup}\left(\frac{\text { jumlah siswa }}{\text { jumlah maksimum siswa } 1 \text { kelas }}\right)+2$

f. Rasio kebutuhan buku perpustakaan : jumlah peserta didik $=$

- Jumlah buku pengayaan $\leq 168$ peserta didik $=100$ buku

- jumlah buku pengayaan 336 peserta didik = 1500 buku

- jumlah buku pengayaan 672 peserta didik $=2000 \mathrm{buku}$

- jumlah buku teks pelajaran $=($ jumlah siswa $*$ jumlah mata pelajaran $)+$ (jumlah mata pelajaran $* 2$ )

- jumlah buku panduan pendidik $=($ jumlah mata pelajaran $*$ jumlah guru $)+$ jumlah mata pelajaran

- jumlah buku fiksi $=40 \% * 840$

- jumlah buku non fiksi $=60 \% * 840$

- jumlah buku referensi dan buku sumber belajar lain $=10$ buku 
g. Rasio kebutuhan perabot perpustakaan : sekolah =

- Rak (Buku, majalah, surat kabar), lemari, papan informasi, meja multimedia, buku inventaris = 1 buah/sekolah

- Meja baca, kursi baca $=10$ buah/sekolah

- Jumlah petugas perpustakaan $=3$ orang

- Kursi petugas, meja petugas, = jumlah petugas perpustakaan

h. Rasio kebutuhan Lab IPA : sekolah =

- Lemari, model tubuh dan kerangka manusia, model tata surya, poster IPA = 1 buah/sekolah

- Kaca pembesar, cermin dan lensa(datar, cekung, cembung), magnet = 6 buah/sekolah

i. Rasio kebutuhan ruang pimpinan : sekolah $=$

- Kebutuhan ruang pimpihan $=1$ buah/sekolah

j. Rasio luas ruang guru : jumlah guru $=$

- Jika jumlah guru $\leq 8=32 \mathrm{~m}^{2}$

- Jika jumlah guru $\geq 8=$ jumlah guru $* 4 \mathrm{~m}^{2}$

k. Rasio jumlah guru : perabot ruang guru $=$

- Kursi guru, meja guru, lemari guru = jumlah guru

- Lemari, papan, tempat sampah, tempat cuci tangan, jam, penanda waktu = 1 buah/sekolah

1. Rasio luas tempat ibadah : jumlah pengguna tempat ibadah $=$

- Jika jumlah peserta didik + jumlah guru $\leq 24=12 \mathrm{~m}^{2}$

- Jika jumlah peserta didik + jumlah guru $\leq 28=$ (jumlah siswa + jumlah guru) $* 0.5$

- Jika jumlah peserta didik + jumlah guru $\geq 28=14 \mathrm{~m}^{2}$

m. Rasio jumlah tempat ibadah : perabot tempat ibadah $=$

- Lemari/rak, jam dinding = 1buah/tempat ibadah

- perlengkapan ibadah $=24$ hingga 28 buah

n. Rasio jumlah UKS : perabot UKS =

- Kursi = 2 buah/UKS

- Tempat tidur, Lemari, Meja, catatan, P3K, tandu, selimut, alat kesehatan, tempat sampah, tempat cuci tangan, jam diniding $=1$ buah/UKS

o. Rasio jumlah jamban : jumlah peserta didik =

- Jumlah jamban $=$ Rounddown $\left(\right.$ jumlah $\left.\frac{\text { siswa }}{\text { luas jamban perempuan+laki-laki }}\right) * 2$

- Luas jamban $=$ jumlah jamban $* 2$

p. Rasio jumlah jamban : perabot jamban $=$

- Perabot jamban = jumlah jamban

q. Rasio jumlah gudang : perabot gudang $=$

- Lemari, rak = 1 buah/gudang

r. Rasio luas tempat olahraga : jumlah peserta didik =

- Jika jumlah peserta didik $\leq 167=500 \mathrm{~m}^{2}$

- Jika jumlah peserta didik $\geq 167=$ jumlah siswa $* 3 \mathrm{~m}^{2}$

s. Rasio kebutuhan tempat olahraga : sekolah =

- Kebutuhan dan peralan olahraga $=1$ buah/sekolah

t. Dana BOS yang diperoleh sekolah : jumlah peserta didik

- Dana BOS yang diperoleh sekolah = jumlah siswa $* 900000$ 
u. Pengalokasian dana BOS : total dana BOS =

- Dana BOS yang diperoleh sekolah $=$ jumlah siswa $* 900000$

- Dana pengembangan perpustakaan $=14.63 \%$ * dana BOS yang diperoleh sekolah

- Dana penerimaan siswa baru $=2.66 \% *$ dana BOS yang diperoleh sekolah

- Dana pembelajaran dan ekstrakulikuler $=11.97 \%$ * dana BOS yang diperoleh sekolah

- Dana evaluasi pembelajaran $=5.35 \% *$ dana BOS yang diperoleh sekolah

- Dana pembagian pengelolaan sekolah $=23.94 \% *$ dana BOS yang diperoleh sekolah

- Dana pengembangan profesi $=3.99 \% *$ dana BOS yang diperoleh sekolah

- Dana langganan daya dan jasa $=6.65 \% *$ dana BOS yang diperoleh sekolah

- Dana pemeliharaan dan perawatan sarpras $=7.98 \% *$ dana BOS yang diperoleh sekolah

- Dana pembayaran tenaga honorer $=7.98 \%$ * dana BOS yang diperoleh sekolah

- Dana pembelian dan perawatan media pembelajaran $=10.64 \% *$ dana BOS yang diperoleh sekolah

- Dana biaya lain $=3.99 \% *$ dana BOS yang diperoleh sekolah

\section{Grafik}

Tabel 4. Sistematika Input, Proses, dan Output Grafik

\begin{tabular}{|l|l|l|}
\hline \multicolumn{1}{|c|}{ Input } & \multicolumn{1}{|c|}{ Proses } & \multicolumn{1}{c|}{ Output Grafik } \\
\hline Jumlah Siswa & $\begin{array}{l}\text { Implementasi Excel Rumus 1 } \\
\text { hingga Rumus 21 }\end{array}$ & $\begin{array}{l}\text { Gambar 2. Grafik seluruh } \\
\text { kebutuhan sekolah : jumlah siswa }\end{array}$ \\
\hline Jumlah Siswa & $\begin{array}{l}\text { Implementasi Excel Rumus 1 dan } \\
\text { Rumus 2 }\end{array}$ & $\begin{array}{l}\text { Gambar 3. Grafik jumlah siswa : } \\
\text { luas kelas dan jumlah kelas }\end{array}$ \\
\hline Jumlah Siswa & Implementasi Excel Rumus 3 & $\begin{array}{l}\text { Gambar 4. Grafik jumlah siswa: } \\
\text { kebutuhan kelas }\end{array}$ \\
\hline Jumlah Siswa & Implementasi Excel Rumus 6 & $\begin{array}{l}\text { Gambar 5. Grafik jumlah siswa: } \\
\text { kebutuhan buku perpustakaan }\end{array}$ \\
\hline
\end{tabular}

Pembuatan grafik menggunakan Microsoft Excel dengan mengimplementasikan syarat syarat yang terdapat pada Tabel 2 . 


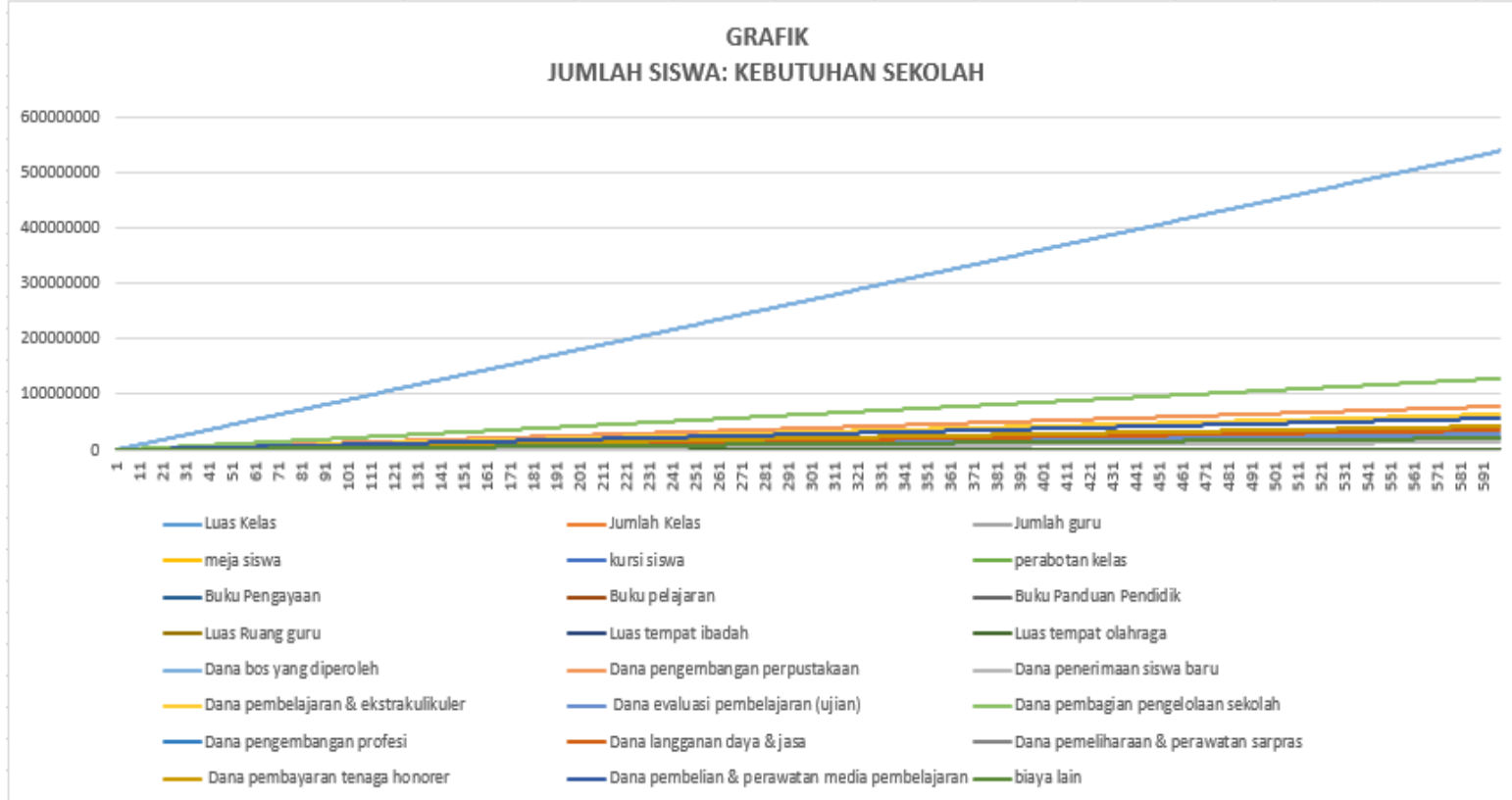

Gambar 2. Grafik seluruh kebutuhan sekolah:jumlah siswa

Untuk memperoleh grafik seperti gambar diatas, user hanya cukup memasukkan jumlah siswa keseluruhan, maka grafik kebutuhan kelas akan muncul. Grafik diatas adalah grafik dengan jumlah siswa 1 hingga 598. Namun, grafik tersebut dapat diimplementasikan hingga jumlah maksimal siswa dalam suatu sekolah yakni 672 siswa. Grafik tersebut menerapkan Rumus 1 hingga Rumus 21. Berikut terdapat beberapa sampel grafik hubungan antar SNP, yaitu:

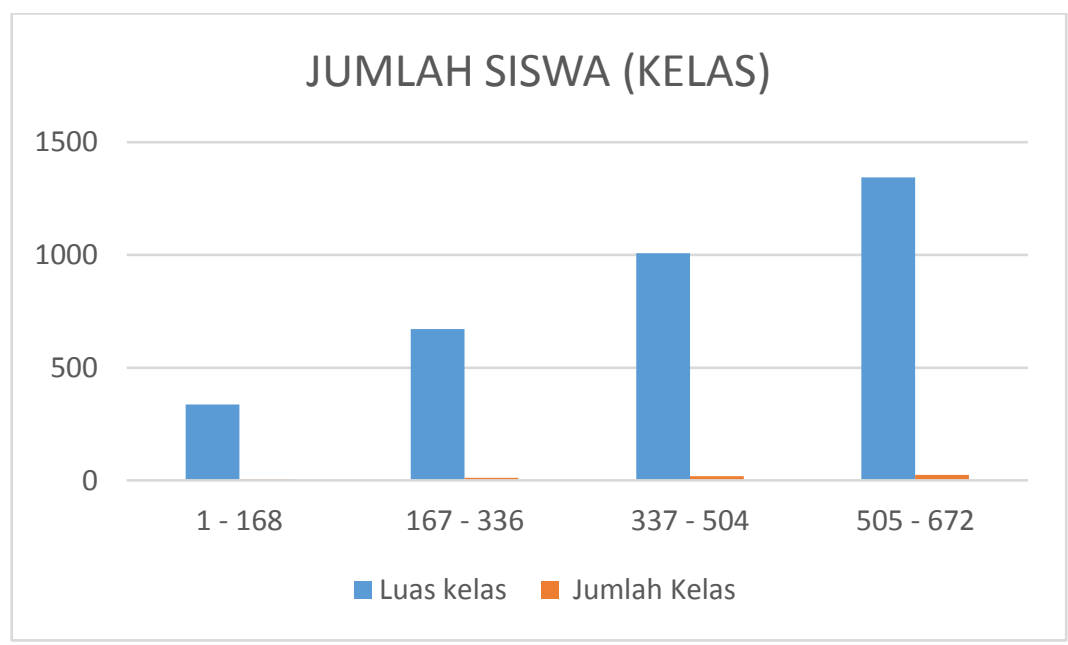

Gambar 3. Grafik jumlah siswa : luas kelas dan jumlah kelas

Untuk memperoleh grafik diatas, kita lihat Tabel 3. Disana dituliskan syarat masing masing rombongan. Dari syarat itulah bisa dikaitkan dengan Rumus 1 dan Rumus 2 serta diimplementasikan dalam Microsoft Excel sehingga terbentuklah grafik yang demikian. Misal, jumlah siswa 336 maka dengan mengimplementasikan Rumus 1 dimana luas kelas = jumlah siswa *2m, maka luas kelas yang dihasilkan adalah $672 \mathrm{~m}^{2}$ dan dengan menggunakan rumus 2 dimana Jumlah kelas $=\operatorname{Roundup}\left(\frac{\text { jumlah siswa }}{\text { jumlah maksimum siswa } 1 \text { kelas }}\right)$ 
maka jumlah kelas yang dibutuhkan adalah 12 kelas. Dapat dilihat pada grafik diatas, telah sesuai dengan perhitungan yang dilakukan. Begitu pula penerapan rumus dan tabel syarat dalam mendapatkan berbagai grafik lainnya.

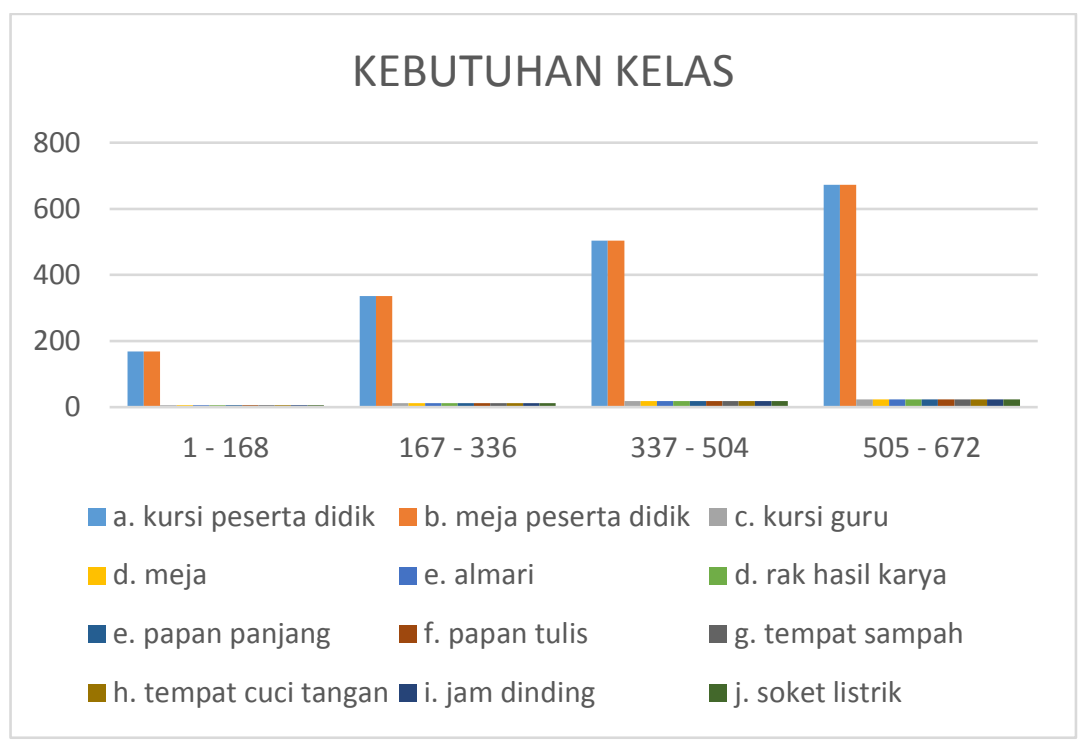

Gambar 4. Grafik jumlah siswa : kebutuhan kelas

Untuk memperoleh grafik diatas, kita lihat Tabel 3. Disana dituliskan syarat masing masing rombongan. Dari syarat itulah bisa dikaitkan dengan Rumus 3 serta diimplementasikan dalam Microsoft Excel sehingga terbentuklah grafik yang demikian.

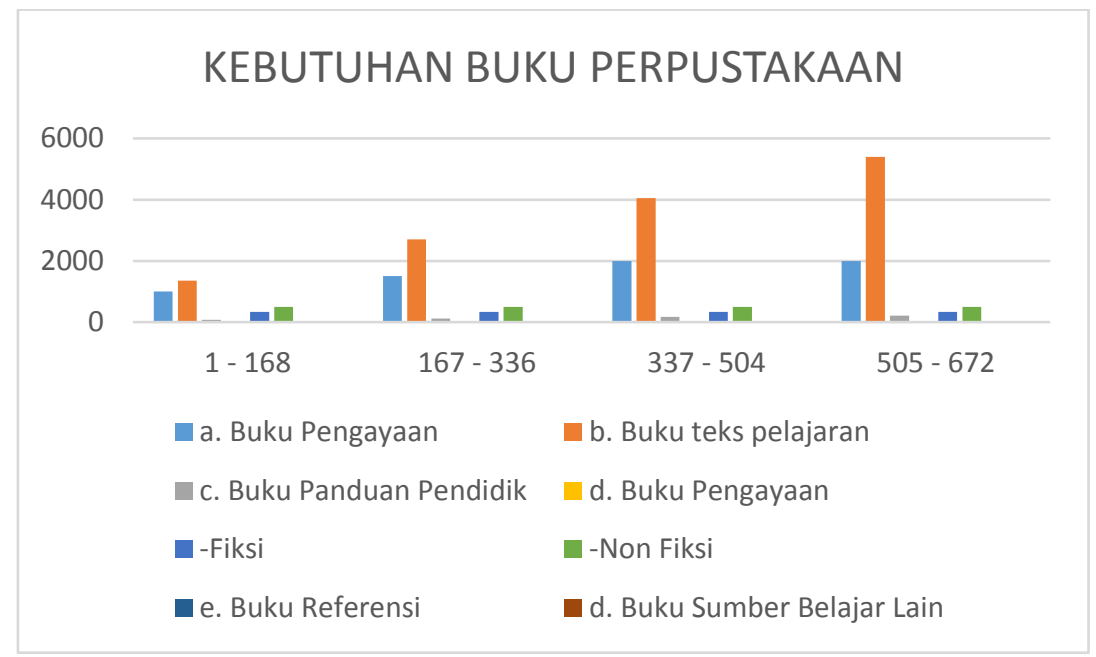

Gambar 5. Grafik jumlah siswa : kebutuhan buku perpustakaan

Untuk memperoleh grafik diatas, kita lihat Tabel 3. Disana dituliskan syarat masing masing rombongan. Dari syarat itulah bisa dikaitkan dengan Rumus 6 serta diimplementasikan dalam Microsoft Excel sehingga terbentuklah grafik yang demikian.

\section{KESIMPULAN}

Berdasarkan hasil penelitian Analisis dan Perancangan Software Simulasi Pertumbuhan Kebutuhan Proses Bisnis Sekolah Berdasarkan SNP dapat diambil kesimpulan bahwa jumlah siswa memberikan pengaruh terhadap berbagai kebutuhan sekolah, mulai dari jumlah kelas yang dibutuhkan hingga bertambahnya sarana dan prasarana sekolah sebagai penunjang kebutuhan. Program dibuat menggunakan Microsoft Excel dengan input jumlah 
siswa dan dapat menyajikan 2 jenis grafik yaitu grafik masing - masing perbandingan rasio maupun grafik secara keseluruhan. Berdasarkan penelitian ini, peneliti mengusulkan untuk kedepannya bagi pembaca agar dapat melakukan penelitian lebih lanjut tentang 8 SNP atau aturan - aturan lain yang mampu menunjang program yang akan dibuat sehingga dapat dengan maksimal digunakan oleh berbagai sekolah.

\section{REFERENSI}

[1] Z. Yan, M. Mazzara, E. Cimpian, and A. Urbanec, "Business process modeling: Classification and perspective,” Bus. Process Model. Classif. Perspect., no. May 2014, pp. 222-227, 2007.

[2] M. S. Al Ayyubi, M. Fadhil, A. Amal, and M. A. Yaqin, "Analisis pola pertumbuhan kebutuhan sekolah," Anal. POLA PERTUMBUHAN KEBUTUHAN Sekol., no. December 2019, pp. 67-74, 2020.

[3] P. Pemerintah, R. Indonesia, and P. R. Indonesia, "PP RI 322013 tentang standar nasional pendidikan," pp. 1-16, 2013.

[4] D. I. S. Ma and M. Wonosobo, "Analisis pemenuhan 8 standar nasional pendidikan di sma muhammadiyah wonosobo," no. 1, pp. 1-22.

[5] R. S. Wahono, "KONTRIBUSI PENELITIAN DAN PERBAIKAN METODE.” 2014, [Online]. Available: https://romisatriawahono.net/2014/01/10/kontribusi-penelitian-dan-perbaikan-metode/.

[6] P. M. P. D. K. R. INDONESIA, "PEDOMAN PENDIRIAN, PERUBAHAN, DAN PENUTUPAN SATUAN PENDIDIKAN DASAR DAN MENENGAH," PEDOMAN PENDIRIAN, PERUBAHAN, DAN PENUTUPAN SATUAN Pendidik. DASAR DAN MENENGAH, vol. 9, no. 1, pp. 76-99, 2010, doi: 10.1558/jsrnc.v4il.24.

[7] D. J. P. Perundang-undangan, “LEMBARAN NEGARA,” Sist. Pendidik. Nas., no. 78, pp. 1-23, 2003.

[8] G. W. Sasmito, "Penerapan Metode Waterfall Pada Desain Sistem Informasi Geografis Industri Kabupaten Tegal," J. Inform. Pengemb. IT, vol. 2, no. 1, pp. 6-12, 2017.

[9] Kemdikbud, "Kementerian Pendidikan dan Kebudayaan," Http://Kemdikbud.Go.Id/, no. 021, p. , 2017, [Online]. Available: http://kemdikbud.go.id/main/?lang=id.

[10] P. Format, K. R. Laporan, and D. Bos, "Acuan 11 komponen penggunaan dana bos masuk kedalam 8 standar program/kegiatan sekolah pada format k.7 (rekap laporan dana bos) 8," vol. 7, pp. 1-4.

[11] M. P. dan K. RI, "Permendikbud No. 21 Tahun 2016 - Standar Isi Pendidikan Dasar dan Menengah," 2016.

[12] PERATURAN MENTERI PENDIDIKAN DAN KEBUDAYAAN REPUBLIK INDONESIA, "Permendikbud Tahun2016_Nomor020," STANDAR KOMPETENSI LULUSAN Pendidik. DASAR DAN MENENGA $H$, no. Standar Kompetensi Lulusan, pp. 1-3, 2016.

[13] Kemendikbud, "Salinan Permendikbud Nomor 23 tahun 2016 Tentang Standar Penilaian Pendidikan," Peratur. MENTERI Pendidik. DAN Kebud. REPUBLIK Indones., no. Standar Penilaian Pendidikan, pp. 1-12, 2016, doi: http://dx.doi.org/10.1016/j.athoracsur.2009.09.030.

[14] Permendikbud, "Peraturan Menteri Pendidikan dan Kebudayaan Republik Indonesia Nomor 22 Tahun 2016 tentang Standar Proses Pendidikan Dasar dan Menengah," J. Chem. Inf. Model., vol. 53, no. 9, pp. 1689-1699, 2016, doi: 10.1017/CBO9781107415324.004.

[15] M. P. N. R. Indonesia, "STANDAR SARANA DAN PRASARANA UNTUK SEKOLAH DASAR/MADRASAH IBTIDAIYAH $\quad$ (SD/MI), SEKOLAH $\quad$ MENENGAH PERTAMA/MADRASAH TSANAWIYAH (SMP/MTs), DAN SEKOLAH MENENGAH ATAS/MADRASAH ALIYAH (SMA/MA)," STANDAR SARANA DAN PRASARANA UNTUK Sekol. DASAR/MADRASAH IBTIDAIYAH (SD/MI), Sekol. MENENGAH PERTAMA/MADRASAH TSANAWIYAH (SMP/MTs), DAN Sekol. MENENGAH ATAS/MADRASAH ALIYAH, no. 235, p. 245, 2007.

[16] P. M. P. NASIONAL, "Oleh Satuan Pendidikan Dasar Dan Menengah a . Perencanaan Program," STANDAR PENGELOLAAN Pendidik. OLEH SATUAN Pendidik. DASAR DAN MENENGAH, pp. 120, 2007.

[17] M. P. N. R. INDONESIA and PERATURAN, "STANDAR TENAGA PERPUSTAKAAN SEKOLAH/MADRASAH,” STANDAR TENAGA Perpust. SEKOLAH/MADRASAH, pp. 5-6, 2008. 